\title{
Continuous recycling of enzymes during production of lignocellulosic bioethanol in demonstration scale
}

\author{
Mai Østergaard Haven ${ }^{\mathrm{a}, \mathrm{b}, *}$, Jane Lindedam ${ }^{\mathrm{b}}$, Martin Dan Jeppesen ${ }^{\mathrm{a}}$, Michael Elleskov ${ }^{\mathrm{a}}$, \\ Ana Cristina Rodrigues ${ }^{c}$, Miguel Gama ${ }^{c}$, Henning Jørgensen ${ }^{\mathrm{b}, 1}$, Claus Felby ${ }^{\mathrm{b}}$ \\ ${ }^{a}$ DONG Energy, Kraftværksvej 53, DK-7000 Fredericia, Denmark \\ ${ }^{\mathrm{b}}$ Department of Geosciences and Natural Resource Management, University of Copenhagen, Rolighedsvej 23, DK-1958 Frederiksberg C, Denmark \\ ${ }^{\mathrm{c}}$ IBB-Institute for Biotechnology and Bioengineering, Centre for Biological Engineering, Minho University, Campus de Gualtar, 4710-057 Braga, Portugal
}

\section{H I G H L I G H T S}

- Results from continuous experiments in demonstration scale for a total of 16 days.

- Reuse of enzymes is possible through recycling fermentation broth.

- Recycling fermentation broth can increase ethanol concentration with lower dry matter.

\section{A R T I C L E I N F O}

\section{Article history:}

Received 6 January 2014

Received in revised form 23 June 2015

Accepted 16 August 2015

\section{Keywords:}

Enzyme recovery

Enzyme recycling

Wheat straw

Enzymatic hydrolysis

Fermentation

High dry matter content

\begin{abstract}
A B S T R A C T
Recycling of enzymes in production of lignocellulosic bioethanol has been tried for more than 30 years. So far, the successes have been few and the experiments have been carried out at conditions far from those in an industrially feasible process. Here we have tested continuous enzyme recycling at demonstration scale using industrial process conditions (high dry matter content and low enzyme dosage) for a period of eight days. The experiment was performed at the Inbicon demonstration plant (Kalundborg, Denmark) capable of converting four tonnes of wheat straw per hour. $20 \%$ of the fermentation broth was recycled to the hydrolysis reactor while enzyme dosage was reduced by $5 \%$. The results demonstrate that recycling enzymes by this method can reduce overall enzyme consumption and may also increase the ethanol concentrations in the fermentation broth. Our results further show that recycling fermentation broth also opens up the possibility of lowering the dry matter content in hydrolysis and fermentation while still maintaining high ethanol concentrations.
\end{abstract}

() 2015 Elsevier Ltd. All rights reserved.

\section{Introduction}

The recycling of enzymes in production of bioethanol from lignocellulosic biomass aiming at reducing enzyme consumption and thereby production costs have been investigated for many years and by many different approaches. These typically involve either contact between the lignin-rich residue after hydrolysis/ fermentation and fresh cellulose containing substrate [1-5], different methods for recycling process liquids or combinations thereof [6]. Liquid recycling is furthermore often combined with

\footnotetext{
* Corresponding author at: DONG Energy, Kraftværksvej 53, DK-7000 Fredericia, Denmark. Tel.: +459955 2906.

E-mail address: maope@dongenergy.dk (M.Ø. Haven).

1 Present address: Department of Chemical and Biochemical Engineering, Technical University of Denmark, Søltofts Plads, Building 227, DK-2800 Kgs. Lyngby, Denmark.
}

other process steps e.g. pH adjustment [7-11] or alkaline elution [12] to desorb enzymes prior to separation or membrane filtration to concentrate the enzymes and reduce the amount of water to be recycled $[13,14]$. Previously published experiments with enzyme recycling show that the cellulolytic activity remaining after hydrolysis and fermentation is found both free in solution and adsorbed to the residual solids [15] - often most of the cellulases are adsorbed to the residual solids [3,4]. The amount of adsorbed activity depends on the type of biomass, the type of pretreatment [16], and the type of enzyme [17]. Therefore, recycling methods need to be adapted to the individual pretreatment process and should include either recycling of both liquid and solids or a method for protein desorption (e.g. one of the methods mentioned earlier).

Commercial cellulase preparations for hydrolysis of pretreated biomass contain different enzyme activities to ensure efficient 
hydrolysis. These include cellulases (endo- and exoglucanases) hemicellulases, $\beta$-glucosidases, oxidative enzymes, esterases and several others [18-21]. This mixture of different activities complicates the recycling process since each enzyme behaves differently with regard to stability during the process and adsorption to cellulose and/or lignin.

A key challenge in recycling of cellulase preparations is the rather variable adsorption of cellulases and $\beta$-glucosidases to the matrix of lignocellulosic biomass $[4,15,17,22,23]$. Therefore, from a point of process simplicity, the best results for enzyme recycling may be obtained when the whole fermentation broth is reintroduced to the hydrolysis step.

With regard to enzyme recycling, adsorption to the biomass during the process of cellulose hydrolysis and the irreversible loss of some of the cellulase activities are both major challenges. This can be due to a number of factors such as denaturation from the residence time at elevated temperature [23], enzyme precipitation [24], shear stress (from agitators, flow and pumps) [25-30] and/or denaturation from contact with the air-liquid interphase. We have previously shown that depending on the cellulase preparation, residence time, and temperature, $35-75 \%$ of the cellulase activity is irreversibly lost when the cellulases are incubated in buffer without substrate [23]. However, we lack knowledge on the levels of individual cellulase activities in a continuous industrial process, where denaturation, inhibition, and lignin build-up might reduce the enzyme recycling potential severely.

Recently, Weiss et al. [31] have shown that significant amounts of cellulase activity can be recycled through recycling the residual solids making it possible to reduce the enzyme dosage by $30 \%$ and still reach the same glucose yields. Tu et al. [32] have optimised a method for enzyme desorption from the residual solids using $0.5 \%$ Tween 80 at app. $44^{\circ} \mathrm{C}$ and pH 5.3 resulting in a cellulose conversion after three successive rounds of recycling of $88 \%$. However, most of the published experiments have been carried out at conditions that are not feasible in an industrial process for production of advanced bioethanol. A major problem is typically that the hydrolysis have been carried out at low dry matter content (2-15\%), high enzyme loadings and with advanced setups for separation and enzyme recovery, which are not possible or realistic to implement on a larger scale.

In 2009, DONG Energy started operating the Inbicon demonstration plant in Kalundborg (Denmark). The plant is capable of processing four tonnes of wheat straw per hour and wheat straw is currently converted into three products; ethanol, a C5 molasses (for production of biogas, animal feed or bioethanol), and solid lignin biofuel (for production of green electricity and heat). A thorough description of the demonstration plant has been published previously [33]

The aim of this work was to test enzyme recycling by recycling fermentation broth in the Inbicon demonstration plant at a dry matter above $20 \%$ content and in a continuous production run over an extended period. We have taken an approach of process simplicity when testing enzyme recycling at demonstration scale by continuously recycling $20 \%$ of the fermentation broth to the first hydrolysis stage. According to our previous findings [23], the fermentation broth was the most promising stream to recycled as it had a higher activity than the distillation broth while containing less inhibitory compounds than the hydrolysis mash. The experimental setup can be seen in Fig. 1. The demonstration scale experiment was carried out in two parts each app. eight days - first a reference phase without enzyme recycling followed by a recycling phase where the fermentation broth produced in the reference run was recycled to the hydrolysis. During both phases cellulose conversion, ethanol yield, and the activities of Cel7A (cellobiohydrolase I), Cel7B (endoglucanase I), and $\beta$-glucosidase were monitored.

\section{Results and discussion}

\subsection{Continuous enzyme recycling in demonstration scale}

During the recycling test, the level of recycled fermentation broth was monitored by measuring the ethanol concentration in the hydrolysis mash and the recycled fermentation broth; the ethanol concentration could then be used as an internal standard to calculate the degree of recycling (according to Eq. (1)). Data from the experiment confirmed that an overall recycling degree of $18 \%$ (0.18) was achieved.

In the recycling run, the enzyme loading was reduced by $5 \%$ compared to the reference run. The $5 \%$ reduction was chosen based on our previous laboratory scale findings of low enzyme stability combined with the level of enzyme activity generally observed in samples of fermentation broth from pilot- and demonstration scale [23]. The previous studies yielded total recoveries of cellulase activity of $59 \%$ and $41 \%$ depending on enzyme preparation in the complete fermentation broth [23]. However, in reality it is not possible to recycle the complete broth (as there would be no output from the process) and therefore based on practical considerations it was decided to recycle $20 \%$ of the fermentation broth. This amount should correspond roughly to recycling of $5 \%$ of initial activity and thereby enable a $5 \%$ reduction of initial enzyme loading. Furthermore, the addition of water to the pretreated biomass was reduced in the recycling run compared to the reference run to compensate for the addition of fermentation broth and keep the dry matter content identical in both reference and recycling run (app. 20.5\%). A 5\% reduction in enzyme level is a minor change and demands great attention to measurements as well as process parameters.

The conversion of cellulose during hydrolysis for the reference and recycling runs can be seen in Fig. 2 (the conversions are calculated according to Eq. (2)). The data for the two runs are fitted to a one-phase association model demonstrating statistical differences between the two ( $p$-value less than 0.0001). However, the models of the experimental data showed that similar conversions could be achieved in the reference and recycling runs, when the mean residence time in the recycling run is extended, although using $5 \%$ less enzyme in the recycling trial. According to the two models, the mean residence time should be extended from app $95 \mathrm{~h}$ in the reference run to app $130 \mathrm{~h}$ in the recycling run to obtain $70 \%$ cellulose conversion.

The slower hydrolysis observed in the recycling run may have been caused by the presence of enzyme inhibitors in the recycled fermentation broth. These include ethanol [34-36], xylose [37], degradation products from the pretreatment [38]. The fact that the hydrolysis levels of around $70 \%$ can also indicate that the remaining 30\% cellulose is rather recalcitrant and therefore difficult to degrade as indicated by Fig. 2. This recalcitrance could either be due to the cellulose structure, i.e. crystallinity, or the increasing concentration of lignin hindering the accessibility of the cellulases to the cellulose [16,39].

However, even though the cellulose conversion is lower in the recycling run than in the reference run the final ethanol concentrations are identical due to the ethanol in the recycled fermentation broth. If the hydrolysis is extended to obtain identical cellulose conversions, this will lead to an increased ethanol concentration in the fermentation broth, which will reduce energy consumption for distillation.

\subsection{Recovery of enzyme activity in demonstration scale}

During the experiment we tested if the adsorbed enzymes in the fermentation broth could be desorbed by alkaline wash using the method previously described by Rodrigues et al. [12]. The method was able to desorb minor amounts of Cel7B whereas no 


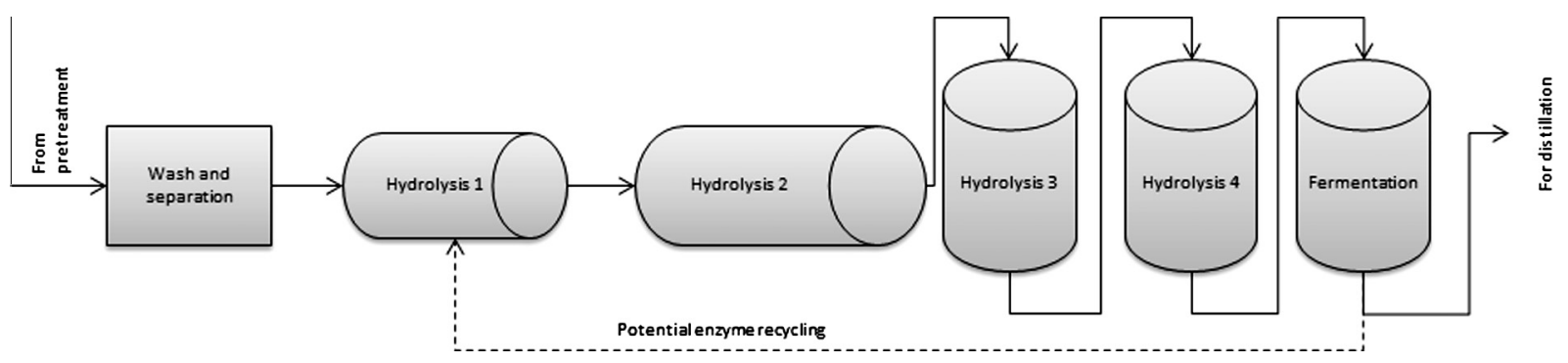

Fig. 1. Overview of part of the demonstration plant and the setup for experiments with recycling of fermentation broth.

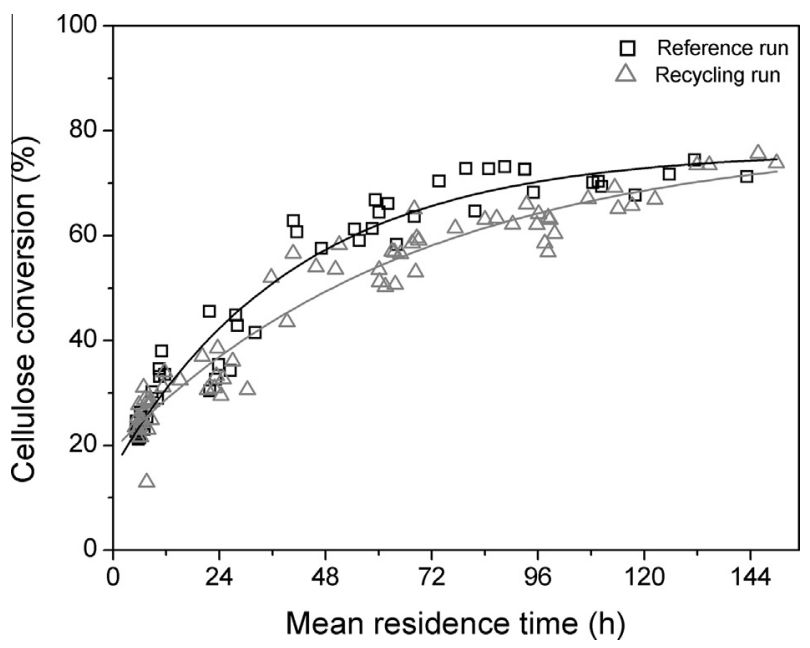

Fig. 2. Cellulose conversion during hydrolysis for reference and recycling run (calculated from Eq. (2); $R^{2}$ for the models: reference run $=0.95$, recycling run $=0.94$ ).

significant desorption of Cel7A and $\beta$-glucosidase was observed making the method unfit for industrial application at the conditions used here. The strong and apparently irreversible adsorption of $\beta$-glucosidase from Cellic ${ }^{\circledR}$ CTec2 to lignin is in accordance with our previously published results [17].

Throughout the experiment in demonstration scale, we also followed the total activities of Cel7A, Cel7B, and $\beta$-glucosidase to evaluate the stability of these enzymes during the process. This was done by measuring the total activity in the hydrolysis mash or fermentation broth in three different tanks of the plant and comparing this with the level of activity added initially. Enzyme activities were marked according to their originating process stage: hydrolysis 1 , hydrolysis 2 and fermentation, see also Fig. 1. The recovery of activity (in percentage of initial activity) for each of the measured enzymes was calculated from Eq. (3) and can be seen in Fig. 3.

When combining data from all stages, we have not been able to prove statistical difference between the reference and the recycling run for any of the enzyme activities even though enzyme addition was reduced by $5 \%$ in the recycling run. For the data analysis, we removed two outliers in the measurements of $\beta$-glucosidase activity.

The fact that there was no significant difference between the reference and recycling run for any of the three activities indicates that the level of enzyme activity was similar and the observation of a slower rate of hydrolysis may indeed have been caused by enzyme inhibitors in the recycled fermentation broth rather than lower level of active enzyme protein.

The data presented in Fig. 3 further reveals, that generally app. $30 \%$ of the initially added activity of the three enzymes was still present in the fermentation broth at the end of the fermentation.
For all three measured enzyme activities, a significant loss of activity was observed after the initial hydrolysis when comparing the measured activity and the added activity (corresponding to $100 \%$ in Fig. 3). A plausible explanation is denaturation or deactivation of the cellulases, which can be caused by shear forces, contact with the air-liquid interphase, elevated temperature, suboptimal $\mathrm{pH}$, or precipitation from dilution of the enzyme. Moreover, Fig. 3 indicates that the total remaining activity of especially Cel7B and $\beta$-glucosidase decreases as the process progresses. Activities of Cel7A, Cel7B and $\beta$-glucosidase were significantly different throughout the tanks, decreasing from hydrolysis 1 to hydrolysis 2 and further to the fermenters $(P>F 0.0147$ for Cel7A and $<0.0001$ for Cel7B and $\beta$-glucosidase, respectively). This trend becomes even clearer when the enzyme activities of Cel7A, Cel7B and $\beta$-glucosidase are shown as function of the mean residence time in hydrolysis during both the reference and recycling run (Fig. 4). The fact that Cel7A seems to be more stable than Cel7B and $\beta$-glucosidase is contrary to earlier findings by Gunjikar et al. [25] and Ye et al. [40] both working with cellulase preparations from Trichoderma reesei. They demonstrated that endoglucanase (like Cel7B) and $\beta$-glucosidase are less denatured by shear forces and therefore more stable than the exoglucanase (like Cel7A).

For all three enzymes, a drop in activity can be seen during the first part of hydrolysis 1 (H1), followed by a more stable level of activity throughout the later hydrolysis (H2) (Fig. 4). Differences appear when examining the slopes of linear trend lines fitted to the recovery of activity in $\mathrm{H} 1$ and $\mathrm{H} 2$ in the reference and recycling run, respectively. When examining the recycling scenario the initial drop in enzyme activity is diminished compared to the reference scenario, hence the negative slopes are less negative (or even positive). Data showing increasing enzyme activity with longer residence times is ascribed to data fluctuations from e.g. sampling, process variations, and determination of mean residence times in a continuous process. However, it seems clear that when recycling the fermentation broth and thereby also adsorbed enzymes the initial loss of enzyme activity is less severe than in the reference run. One explanation could be that the total activity was higher due to the recycling. Another explanation could be that recycling fermentation broth introduces substrate with adsorbed enzyme shielding part of the lignin surface. The adsorbed enzymes prevent non-productive binding of the new enzymes. Rahikainen et al. [41] have earlier suggested that adsorption to lignin at hydrolysis temperatures can lead to heat-induced denaturation on the surface of softwood lignin. If this is the case in our recycling experiment, the extra bonus of recycling includes reduced nonproductive binding to lignin, reduced enzyme denaturation, and stabilised enzyme activities.

\subsection{Batch experiments with enzyme recycling in pilot-scale}

To verify the observations from the continuous recycling, we performed identical experiments in a batch process at pilot-scale. The advantage of doing batch experiments is that all inputs are 
(a)

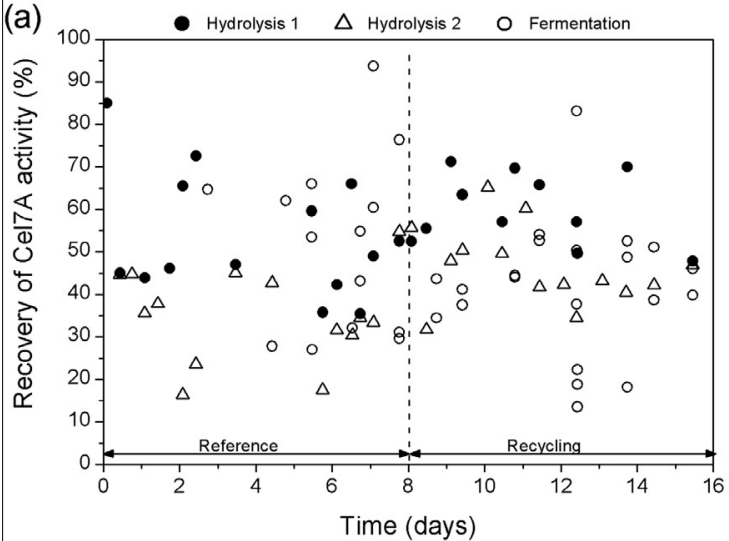

(c)

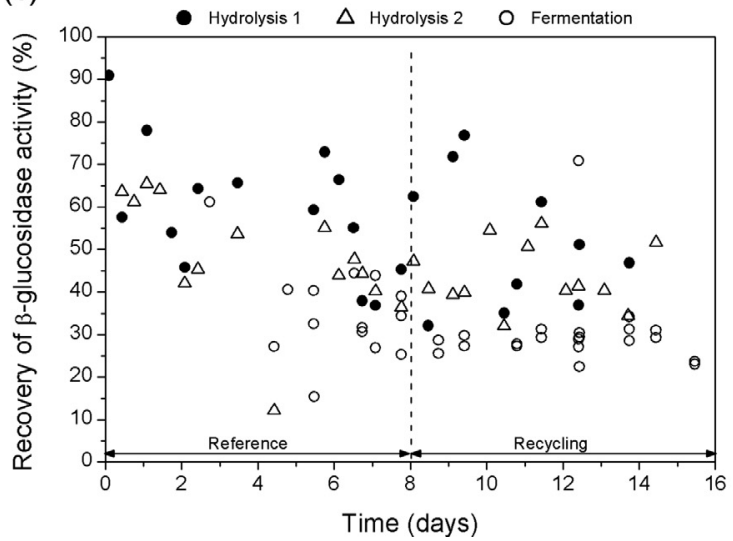

(b)

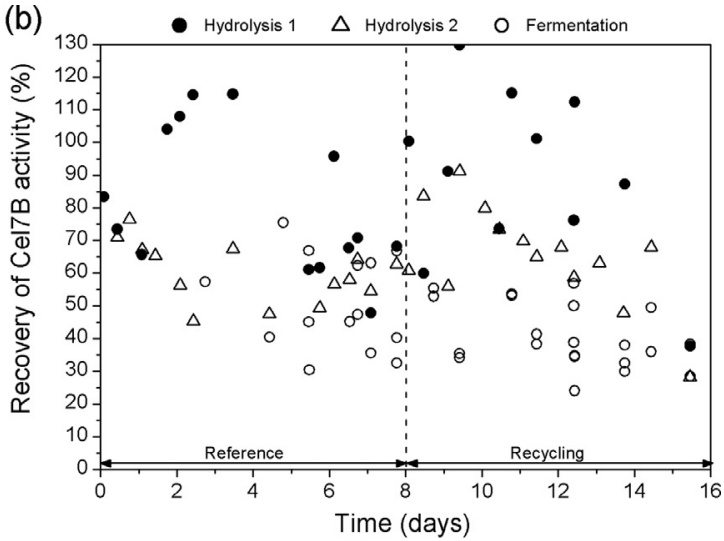

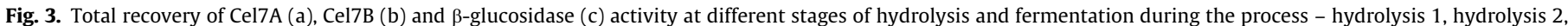
and fermentation.

fixed. The experiment in demonstration scale indicated that the fermentation broth contained compounds inhibiting the hydrolysis. It was therefore investigated, if the addition of fermentation broth inhibited the hydrolysis. This was done by comparing the effect on the hydrolysis and fermentation of pretreated wheat straw by the addition of $20 \%$ fermentation broth untreated or boiled. Identical to the experiment in demonstration scale, the addition of water was lowered in the experiments with recycled fermentation broth to achieve identical dry matter contents. The results confirmed that the recycled fermentation broth inhibited the hydrolysis and decreased the cellulose conversion. In the experiment with the untreated fermentation broth the conversion was $67.8 \pm 0.1 \%$ and when the fermentation broth was boiled prior to addition the conversion was $58.3 \pm 2.0 \%$ (without recycling fermentation broth the cellulose conversion was $70.2 \pm 0.5 \%$ ). However, just as important it confirmed that the recycled fermentation broth did contain a significant amount of cellulase activity due to the higher conversion in the experiment with untreated fermentation broth.

Removal of the inhibiting compound(s) could maybe be of relevance if it does not compromise enzyme activity. However, this would require additional studies to identify the most potent inhibitors, which was outside the scope of the present work. Ethanol is known to inhibit cellulases, but results from previous studies have shown that ethanol removal results in considerable loss of enzyme activity [23].

Instead of doing a comparison based on identical dry matter contents, we also performed a series of experiments in pilotscale focusing on reaching identical final ethanol concentrations with lower enzyme loading, as the ethanol output and the enzyme consumption are essential when evaluating the feasibility of an industrial process.

To obtain identical potential final ethanol concentrations in experiments with and without recycling $20 \%$ fermentation broth, this requires increasing the dry matter content in the reference without enzyme recycling from $20.5 \%$ to $23 \%$. Fig. 5 shows the conversion of cellulose to ethanol at the end of the experiment for the reference case (23\% DM, 100\% enzyme) and various recycling cases (20\% recycled fermentation broth, $20.5 \%$ DM and $80-110 \%$ enzyme). The cellulose conversion and thereby also the ethanol concentration in the fermentation broth was significantly lower in the reference case showing that recycling of the fermentation broth can potentially increase cellulose conversion and the final ethanol output nearly $10 \%$ - or result in identical cellulose conversion and ethanol outputs with addition of less enzyme. Using $20 \%$ recycled fermentation broth; the enzyme dosage can be reduced by app. $15 \%$ while still obtaining identical cellulose conversions and final ethanol output. The large effect of recycling was a combined effect originating from the cellulolytic activity in the recycled material and a decrease in the amount of water insoluble solids.

Recycling enzymes through the fermentation broth enables reduction of the enzyme loading while either obtaining identical final ethanol concentrations (and lowering the dry matter content) or obtaining higher ethanol concentrations (while maintaining identical dry matter contents). The two different scenarios lead to differences in the potential enzyme reduction due to the differences in e.g. dry matter contents and addition of water. The largest reduction in enzyme consumption (app. 15\%) was observed when the dry matter was lowered in the recycling run while maintaining an identical ethanol output. However, to evaluate which one of the 
(a)

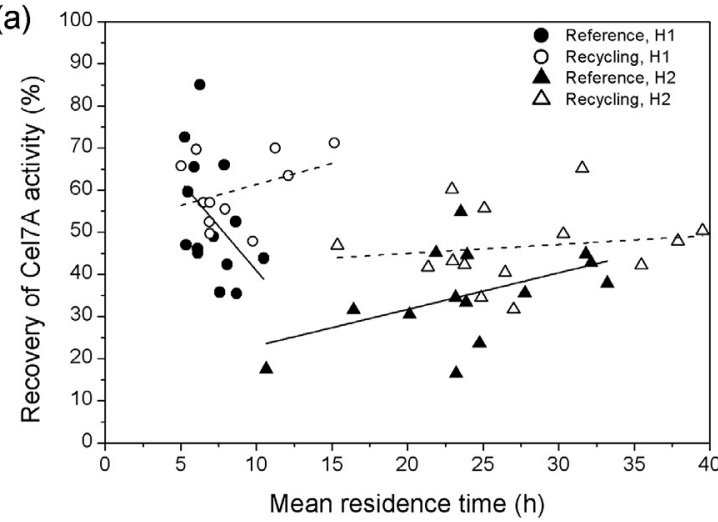

(c)

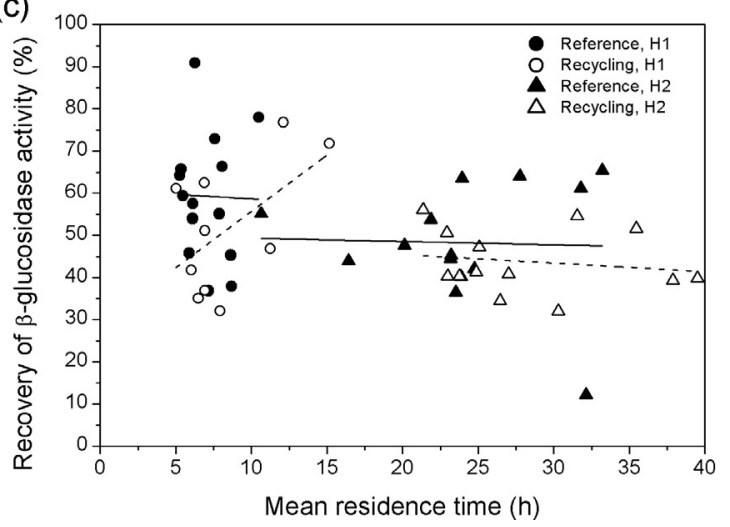

(b)

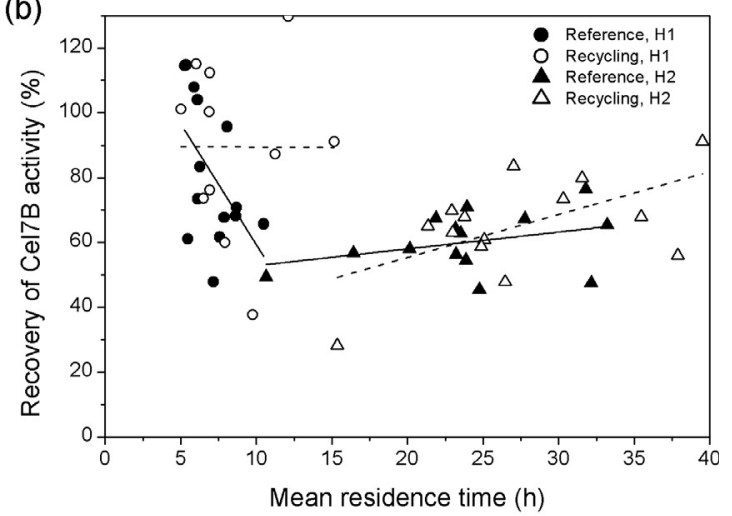

reference and recycling run.

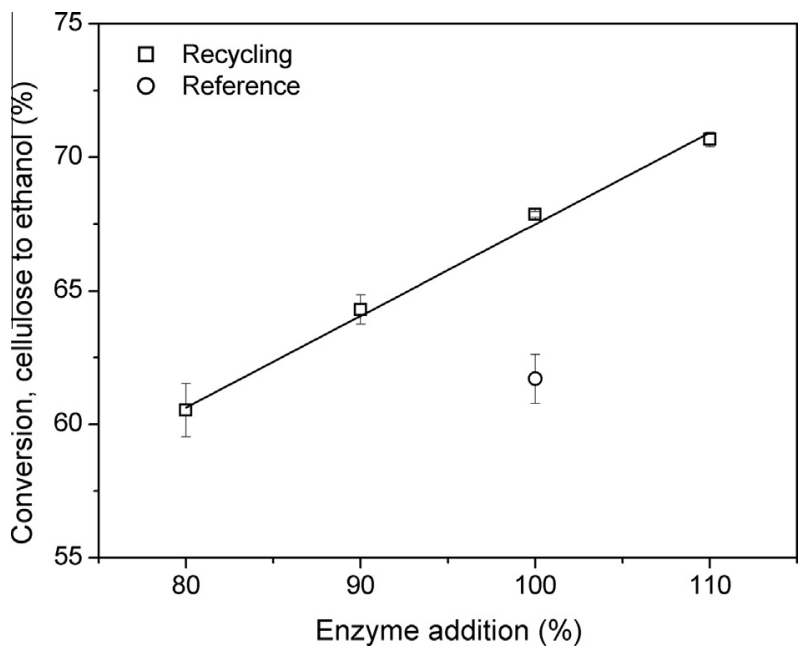

Fig. 5. Cellulose conversion in fermentation broth in pilot-scale experiments with identical ethanol potentials. Reference: $23 \%$ DM, 100\% enzyme. Recycling: $20.5 \%$ DM, $20 \%$ fermentation broth recycled, $80-110 \%$ enzyme (linear fit: $R^{2}=0.98$ ).

two methods that are superior requires thorough modelling of the complete process including e.g. prices for raw materials and energy as well as mass and energy balances.

Furthermore, if enzyme recycling by the method used here should lead to even larger reductions in enzyme loading it will require cellulase preparations that are more stable at process conditions. This is not only true for the cellulase preparation used here (Cellic ${ }^{\circledR} \mathrm{CTec} 2$ ); other publications have suggested the commercial cellulase preparations may have a general problem with stability at process conditions [23]. The results also suggest that identification and removal of the compound(s) from the fermentation broth that inhibits the hydrolysis would improve the result of enzyme recycling as our results here demonstrate that the fermentation broth not only contains a significant amount of cellulolytic activity but also inhibitors of the hydrolysis. Moreover, if cellulases with lower affinity for lignin were available as suggested by Berlin et al. [42] it may allow for enzyme recycling using the liquid fraction only.

\section{Materials and methods}

\subsection{Raw material}

Wheat straw (Triticum aevestivum L.) was grown, harvested, and baled in large Heston bales (app. 500-550 kg) in Denmark during summer 2012. The composition of the wheat straw, measured by strong acid hydrolysis [43] was: cellulose: 36.8, xylan: 22.7, Arabinan 3.0, lignin (Klason) 20.1, ash 5.8 and acetyl 1.8 (all \% of DM).

\subsection{Continuous recycling experiment in demonstration scale}

The Inbicon demonstration plant capable of continuously converting 4 tonnes of wheat straw per hour has previously been described in detail by Larsen et al. [33]. Since the paper was published, the process has been changed from SSF (simultaneous saccharification and fermentation) to SHF (separate hydrolysis and fermentation) meaning that the residence times in hydrolysis and fermentation have been changed to app. $96 \mathrm{~h}$ for hydrolysis and $48 \mathrm{~h}$ for fermentation.

The experiment described in this paper was divided into two parts; a "reference run" where the plant was run for eight days using 100\% fresh enzyme addition of Cellic ${ }^{\circledR}$ CTec2 and without recycling fermentation broth. The level of enzyme added was 
adjusted to give a $70 \%$ conversion of cellulose. The hydrolysis and fermentation tanks were run to produce fermentation broth, which were to be recycled in the second part of the experiment.

The second part of the experiment, also ran for eight days and was the "recycling run", where fermentation broth from the reference run was recycled continuously to the beginning of hydrolysis along with $95 \%$ fresh enzyme addition of Cellic ${ }^{\circledR}$ CTec2. During the recycling run, the addition of water to the pretreated biomass was reduced allowing for the addition of $20 \%$ fermentation broth while still maintaining the same dry matter content in hydrolysis and fermentation (app. 20.5\%). When the recycling run was initiated, the continuous hydrolysis was restarted in empty hydrolysis tanks to ensure identical start up conditions in the two runs. In the recycling run, the target for the recycling degree was $20 \%$ - or more accurately, the volume of the reintroduced fermentation broth to the total flow should be $20 \%$ per volume. As the hydrolysis mash normally does not contain ethanol, the recycling degree $(R)$ was calculated and monitored using the ethanol concentration in the recycled fermentation broth $\left(C_{E t O H}, F B\right)$ and the ethanol in the hydrolysis mash $\left(C_{E t O H}, H M\right)$ using Eq. (1):

$$
R=\frac{C_{E t O H, H M}}{C_{E t O H, F B}-C_{E t O H, H M}}
$$

Our earlier experiments showed that the fermentation broth would typically contain app. $25 \%$ of the initially added cellulolytic activity [23] and with a recycling degree of $20 \%$, we estimated that an enzyme reduction of $5 \%$ would be achievable.

Thus, by comparing the results from the reference and the recycling run, we can not only determine if recycling presents any mechanical or chemical problems at industrial scale, but also if the recyclability found under pilot scale conditions can be confirmed in the demonstration plant.

The conversion of cellulose was calculated for each sample from the hydrolysis using the measured concentrations of cellobiose, glucose, as well as the dry matter content (DM). The glucose and cellobiose concentrations $\left(C_{G l u}\right.$ and $\left.C_{C e l}\right)$ were used to calculate the amount of glucose equivalents formed during hydrolysis. The amount of cellulose was calculated from the amount of dry matter in the sample minus the hydrolytic gain (the amount of water added to the biomass as a result of the bond cleavage during hydrolysis) and the average cellulose content (weight percentage of dry matter, $W T_{C e l}$, which was measured online by near infrared spectrophotometry (NIR) during each part of the run).

When calculating the cellulose conversion during the recycling run, the residual dry matter in the recycled fermentation broth needs to be taken into account. The residual dry matter contains mainly lignin and minor amounts of cellulose and xylan. In the calculations of cellulose conversions, we ignore the potential conversion of cellulose in the recycled material, as this is most likely more difficult to degrade than the new pretreated material judging by low hydrolysis rate at the end of hydrolysis, and assume that only the cellulose in the fresh pretreated biomass is converted. For these calculations Eq. (2) is used ( $R$ is zero in the reference run):
Pretreatment settings were identical in the two runs. The dry matter content and the composition of the pretreated fibres were measured online with near infrared spectrophotometry (NIR). The pretreatment time and temperature were adjusted according to the xylan content in the pretreated fibres. Throughout the experimental set point was 6-9\% xylan.

For the experiment Cellic ${ }^{\circledR} \mathrm{CTec} 2$ (Novozymes, Bagsværd, Denmark) was used. Enzyme was dosed according to the flow of the pretreated material and its cellulose content. In the reference run, an enzyme dosage yielding app. 70\% cellulose conversion was used. Experimental conditions for both runs can be seen in Table 1.

Samples were taken at different stages during hydrolysis and fermentation, at least once per day. These were used for process control through measurements of sugars, organic acids, ethanol and fermentation inhibitors (5-(hydroxymethyl)-furfural and furfural), as well as for measurement of dry matter content, and analyses of enzyme activities (Cel7A, Cel7B and $\beta$-glucosidase).

The measured activities of Cel7A, Cel7B and $\beta$-glucosidase were used to evaluate the degradation of enzymes in the process. This was done by comparing the measured activities with the initially added activity during both runs (Eq. (3)):

Recovery of activity $(\%)=\frac{\text { Measured activity }}{\text { Added activity }} \times 100 \%$

Furthermore, a large sample of fermentation broth was removed after app. $150 \mathrm{~h}$ total process time at both runs. These samples were used for additional recycling experiments in a smaller scale.

\subsection{Batch process recycling experiments}

The recycling experiments in demonstration scale were further supported by pilot-scale trials. These were made with a batch of pretreated fibres from the demonstration plant collected during the reference run. The composition measured by strong acid hydrolysis [43] can be seen Table 2 .

The pilot-scale experiments were carried out in a 5-chamber reactor with a total working volume of $8 \mathrm{~kg}$ pretreated biomass. The reactor is specially designed for hydrolysis and fermentation at high dry matter contents (above 20\% DM) and employs the free-fall mixing principle earlier described by Jørgensen et al. [44].

The pilot-scale trial consisted of a series of batch experiments carried out at conditions similar to the ones in the experiment in demonstration-scale as possible, see Table 3. The pilot-scale experiment compared the cellulose conversion and ethanol concentration in experiments with and without recycling fermentation broth from the demonstration plant.

The experiment was carried out at $20.5 \%$ dry matter (or $23 \%$ in the reference experiment) at varying dosages of Cellic ${ }^{\circledR}$ CTec2 (Novozymes, Bagsværd, Denmark) from 80 to $110 \%$ with app. $96 \mathrm{~h}$ prehydrolysis at $50{ }^{\circ} \mathrm{C}$ followed by a decrease in temperature to $32{ }^{\circ} \mathrm{C}$ and addition of active dry yeast per $\mathrm{kg}$ dry matter

$$
\text { Cellulose conversion }=\frac{C_{G l u}+C_{C e l} \frac{360 \frac{g}{m 0 l}}{\frac{342 g}{m o l}}}{1000\left(\left(D M_{H M}-R \times D M_{F B}\right)-\left(C_{G l u}+C_{C e l} \frac{360 \frac{g}{m o l}}{\frac{342 g}{m o l}}\right) \times \frac{18 \frac{g}{m o l}}{\frac{180 g}{m o l}} \times W T_{C e l} \times \frac{180 \frac{g}{m g l}}{162 \frac{g}{m o l}}\right)}
$$

where $D M_{H M}$ is the dry matter content of the hydrolysis mash and $D M_{F B}$ is the dry matter content of the fermentation broth.
(Thermosacc ${ }^{\circledR}$ Dry, Lallemand Ethanol Technology, Canada) and yeast nutrients. The experiment was continued for a total of app. $170 \mathrm{~h}$. 
Table 1

Experimental conditions in both reference and recycling run.

\begin{tabular}{ll}
\hline & Set point \\
\hline Dry matter & $20.5 \%$ \\
Addition of PEG 6000 & App. $1 \%$ of DM \\
Temperature, hydrolysis & $50{ }^{\circ} \mathrm{C}$ \\
Residence time, hydrolysis & $97 \mathrm{~h}$ \\
$\mathrm{pH}$ & $5.0-5.2$ \\
Temperature, fermentation & $32{ }^{\circ} \mathrm{C}$ \\
Residence time, fermentation & $48 \mathrm{~h}$ \\
\hline
\end{tabular}

Table 2

Composition of pretreated wheat straw from demonstration plant.

\begin{tabular}{lc}
\hline Compound & Composition of straw (\% of DM) \\
\hline Cellulose & $48.6 \pm 0.0$ \\
Xylan & $5.5 \pm 0.1$ \\
Arabinan & $0.5 \pm 0.1$ \\
Lignin (Klason) & $34.7 \pm 0.1$ \\
Ash & $6.4 \pm 0.1$ \\
Acetyl & $0.6 \pm 0.1$ \\
\hline
\end{tabular}

Table 3

Experimental conditions in pilot-scale experiments.

\begin{tabular}{ll}
\hline & Set point \\
\hline Dry matter & $20.5 \%$ (or $23 \%$ in reference) \\
Addition of PEG 6000 & $1 \%$ of DM \\
Temperature, hydrolysis & $50{ }^{\circ} \mathrm{C}$ \\
Residence time, hydrolysis & App. $96 \mathrm{~h}$ \\
$\mathrm{pH}$ & $5.0-5.2$ \\
Temperature, fermentation & $32{ }^{\circ} \mathrm{C}$ \\
Residence time, fermentation & App. $72 \mathrm{~h}$ \\
\hline
\end{tabular}

Furthermore, to check the effect of the components in the fermentation broth on the hydrolysis and fermentation an experiment was made where the fermentation broth was boiled prior to recycling. The concentrations of sugars, organic acids, ethanol and inhibitors as well as the dry matter content was measured before and after boiling the fermentation broth for 10 min under lid. The minor amounts of evaporated water and ethanol were replaced by adding fresh water and ethanol.

\section{Analyses}

\subsection{HPLC analyses}

The concentration of glucose, organic acids, and ethanol in samples collected during hydrolysis and fermentation at high dry matter was measured using an UltiMate 3000 HPLC (Thermo Scientific Dionex) equipped with a refractive index detector (Shodex ${ }^{\circledR}$ RI-101). The separation was performed on a Rezex RHM monosaccharide column (Phenomenex) at $80{ }^{\circ} \mathrm{C}$ with $5 \mathrm{mM} \mathrm{H}_{2} \mathrm{SO}_{4}$ as eluent at a flow rate of $0.6 \mathrm{ml} / \mathrm{min}$. Sample preparation was done as described earlier by Jørgensen et al. [44].

\section{2. $\beta$-glucosidase activity}

The measurements of $\beta$-glucosidase activity was done using $p$ nitrophenyl- $\beta$-d-glucopyranoside as substrate as described by Wood and Bath [45] using a method adjusted to 96-well microplates as described previously [23].

\subsection{Cel7A and Cel7B activity}

Activity of Cel7A and Cel7B was determined by adjusting the protocol published by Bailey and Tähtiharju [46] to black bottom 96-well UV fluorescence microplates. Differentiation between activities on 4-Methylumbelliferyl- $\beta$-d-lactopyranoside of Cel7A and Cel7B in enzyme mixtures is possible by specific inhibition of Cel7A [47]. By measuring the joint activity of Cel7A + Cel7B and subtracting the activity in the presence of cellobiose (which inhibits Cel7A), we calculated the individual activities for both enzymes. $\beta$-glucosidase was inhibited with glucose addition in all cases. Enzyme samples were diluted with $\mathrm{Na}$-acetate buffer $(\mathrm{pH}$ 4.8 ) to concentrations within the standard curve produced with 4-methylumbelliferone sodium salt. $10 \mu \mathrm{l}$ enzyme solution and standards were transferred to a black bottom 96-well plate, along with either $10 \mu \mathrm{l} 1 \mathrm{M}$ glucose $(\mathrm{pH} 4.8)$ or $10 \mu \mathrm{l} 1 \mathrm{M}$ glucose $+50 \mathrm{mM}$ cellobiose ( $\mathrm{pH} 4.8$ ).

Then $80 \mu \mathrm{l} 1 \mathrm{mM}$ 4-Methylumbelliferyl- $\beta$-D-lactopyranoside (Sigma-Aldrich, St. Louis, USA, cat. no. M2405) was added as substrate and the plate was covered with self-adhesive foil and placed on a heating block at $50{ }^{\circ} \mathrm{C}$ for $15 \mathrm{~min}$. After incubation, $100 \mu \mathrm{l} \mathrm{stop}$ solution ( $1 \mathrm{M}$ sodium carbonate) was added and the fluorescence was measured at excitation wavelengths of $360 \mathrm{~nm}$ and emission at $460 \mathrm{~nm}$ (FLUOstar Galaxy, BMG labtech, Germany).

\subsection{Statistical analyses}

The statistical analyses comparing the cellulose conversion for the reference and recycling runs were performed using GraphPad Prism version 5.04 for Windows, GraphPad Software, San Diego, California, USA.

Comparisons of specific enzyme activities were done in SAS using Tukey simultaneous tests with proc GLM at a 95\% confidence level (SAS Institute. SAS/STAT User's Guide, Release 6.03 Edition. Cary, NC: SAS Institute Inc; 1988. p. 1028.)

\section{Conclusions}

We have successfully demonstrated recycling of cellulolytic enzymes through part of the fermentation broth with reduced addition of new enzymes during a period of eight days in demonstration scale at industrial conditions (high dry matter content and low enzyme dosage). Proving that mechanically the method can be applied without problems. Furthermore, the results confirmed our earlier findings from pilot scale about the potential for reduction of enzyme addition with this method.

The applicability of the method is restricted by the stability of the enzymes. Improved enzyme stability and removal of enzyme inhibitors in the fermentation broth may also improve the potential for recycling of cellulolytic enzymes at industrial conditions.

\section{Acknowledgements}

Vibeke Ørsted Bonde Nielsen is gratefully acknowledged for technical assistance during experiments in pilot-scale and measurements of $\beta$-glucosidase activity.

M.Ø. Haven wishes to thank the Danish Agency for Science, Technology, and Innovation, grant no. 09-053694 for financial support. The other authors wish to thank the European Seventh Framework Program, grant no. 239379 (the KACELLE project) for financial support.

\section{References}

[1] Emert GH, Blotkamp PJ. Method for enzyme reutilization. Fayetteville, Ark.: U. S.A.: University of Arkansas Foundation; 1980.

[2] Weiss $\mathrm{N}$ et al. Enzymatic lignocellulose hydrolysis: improved cellulase productivity by insolible solids recycling. Biotechnol Biofuels 2013;6(5).

[3] Vallander L, Eriksson KE. Enzyme recirculation in saccharification of lignocellulosic materials. Enzyme Microb Technol 1987;9(12):714-20. 
[4] Ramos LP, Breuil C, Saddler JN. The use of enzyme recycling and the influence of sugar accumulation on cellulose hydrolysis by Trichoderma cellulases. Enzyme Microb Technol 1993;15(1):19-25.

[5] Ramos LP, Saddler JN. Enzyme recycling during fed-batch hydrolysis of cellulose derived from steam-exploded Eucalyptus viminalis. Appl Biochem Biotechnol 1994;45:193-207.

[6] Lee D, Yu AHC, Saddler JN. Evaluation of cellulase recycling strategies for the hydrolysis of lignocellulosic substrates. Biotechnol Bioeng 1995;45(4):328-36.

[7] Reese ET. Elution of cellulase from cellulose. Process Biochem 1982;17(3):2-6.

[8] Otter DE et al. Elution of Trichoderma reesei cellulase from cellulose by $\mathrm{pH}$ adjustment with sodium hydroxide. Biotechnol Lett 1984;6(6):369-74.

[9] Sinitsyn AP et al. Recovery of enzymes from the insoluble residue of hydrolyzed wood. Appl Biochem Biotechnol 1983;8:25-9.

[10] Sinitsyn AP, Bungay HR, Clesceri LS. Enzyme management in the Iotech process. Biotechnol Bioeng 1983;25(5):1393-9.

[11] Du RY et al. Controlled adsorption of cellulase onto pretreated corncob by pH adjustment. Cellulose 2012;19(2):371-80.

[12] Rodrigues AC et al. Recycling of cellulases in lignocellulosic hydrolysates using alkaline elution. Bioresour Technol 2012:110:526-33.

[13] Mores WD, Knutsen JS, Davis RH. Cellulase recovery via membrane filtration. Appl Biochem Biotechnol 2001;91-93:297-309.

[14] Qi B et al. Enzyme adsorption and recycling during hydrolysis of wheat straw lignocellulose. Bioresour Technol 2011:102:2881-9.

[15] Singh A, Kumar PKR, Schügerl K. Adsorption and reuse of cellulases during saccharification of cellulosic materials. J Biotechnol 1991;18(3):205-12.

[16] Nakagame S, Chandra R, Saddler JN. The effect of isolated lignins, obtained from a range of pretreated lignocellulosic substrates, on enzymatic hydrolysis. Biotechnol Bioeng 2010;105(5):871-9.

[17] Haven MØ, Jørgensen $H$. Adsorption of beta-glucosidases in two commerica preparations onto pretreated biomass and lignin. Biotechnol Biofuels 2013;6: 165.

[18] Gao DH et al. Hemicellulases and auxiliary enzymes for improved conversion of lignocellulosic biomass to monosaccharides. Biotechnol Biofuels 2011:4:11.

[19] Selig MJ et al. Synergistic enhancement of cellobiohydrolase performance on pretreated corn stover by addition of xylanase and esterase acitivities. Biores Technol 2008;99:4997-5005.

[20] Vaaje-Kolstad G et al. An oxidative enzyme boosting the enzymatic conversion of recalcitrant polysaccharides. Science 2010;330:219-22.

[21] Öhgren $\mathrm{K}$ et al. Effect of hemicellulose and lignin removal on enzymatic hydrolysis of steam pretreated corn stover. Bioresour Technol 2007;98: 2503-10.

[22] Barsberg S, Selig MJ, Felby C. Impact of lignins isolated from pretreated lignocelluloses on enzymatic cellulose saccharification. Biotechnol Let 2013:35(2):189-95.

[23] Lindedam J et al. Recycling cellulases for cellulosic ethanol production at industrial relevant conditions: potential and temperature dependency at high solid processes. Bioresour Technol 2013;148:180-8.

[24] Chylenski P et al. Precipitation of Trichoderma reesei commercial cellulase preparations under standard enzymatic hydrolysis conditions for lignocelluloses. Biotechnol Lett 2012;34(8):1475-82.

[25] Gunjikar TP, Sawant SB, Joshi JB. Shear deactivation of cellulase, exoglucanase, endoglucanase, and beta-glucosidase in a mechanically agitated reactor. Biotechnol Prog 2001;17(6):1166-8.
[26] Reese ET, Ryu DY. Shear inactivation of cellulase of Trichoderma reesei. Enzyme Microb Technol 1980;2:239-40.

[27] Kim MH et al. Surface deactivation of cellulase and its prevention. Enzyme Microbial Technol 1982;4(2):99-103.

[28] Ganesh K, Joshi JB, Sawant SB. Cellulase deactivation in a stirred reactor. Biochem Eng J 2000;4(2):137-41.

[29] Ghadge RS et al. Effect of flow pattern on cellulase deactivation in stirred tank bioreactors. Chem Eng Sci 2005;60(4):1067-83.

[30] Kaya F, Heitmann JA, Joyce TW. Deactivation of cellulase and hemicellulase in high shear fields. Cellul Chem Technol 1996;30(1-2):49-56.

[31] Weiss $N$ et al. Enzymatic lignocellulose hydrolysis: improved cellulase productivity by insoluble solids recycling. Biotechnol Biofuels 2013;6(5).

[32] Tu M et al. The potential of enzyme recycling during the hydrolysis of a mixed softwood feedstock. Biores Technol 2009;100:6407.

[33] Larsen J, Haven MØ, Thirup L. Inbicon makes lignocellulosic ethanol a commercial reality. Biomass Bioenergy 2012;46:36-45.

[34] Holtzapple $\mathrm{M}$ et al. Inhibition of Trichoderma reesei cellulase by sugars and solvents. Biotechnol Bioeng 1990;36(3):275-87.

[35] Wu Z, Lee YY. Inhibition of the enzymatic hydrolysis of cellulose by ethanol. Biotechnol Lett 1997;19(10):977-9.

[36] Ooshima H, Ishitani Y, Harano Y. Simultaneous saccharification and fermentation of cellulose: effect of ethanol on enzymatic saccharification of cellulose. Biotech Bioeng 1985;27:389-97.

[37] Xiao Z et al. Effects of sugar inhibition on cellulases and beta-glucosidase during enzymatic hydrolysis of softwood substrates. Appl Biochem Biotechnol 2004:115(1-3):1115-26.

[38] Kumar $\mathrm{R}$ et al. Carbohydrate derived-pseudo-lignin can retard cellulose biological conversion. Biotechnol Bioeng 2013;110(3):737-53.

[39] Hansen MAT et al. Pretreatment and enzymatic hydrolysis of wheat straw (Triticum aestivum L.) - The impact of lignin relocation and plant tissues on enzymatic accessibility. Bioresour Technol 2011;102(3):2804-11.

[40] Ye Z, Hatfield KM, Berson RE. Deactivation of individual cellulase components. Bioresour Technol 2012;106:133-7.

[41] Rahikainen J et al. Inhibition of enzymatic hydrolysis by residual lignins from softwood-study of enzyme binding and inactivation on lignin-rich surface. Biotechnol Bioeng 2011;108(12):2823-34.

[42] Berlin A et al. Weak lignin-binding enzymes: a novel approach to improve activity of cellulases for hydrolysis of lignocellulosics. Appl Biochem Biotechnol 2005;121:163-70.

[43] Sluiter A, et al. Determintation of structural carbohydrates and lignin in biomass (NREL/TP-510-42618). National Renewable Energy Laboratory; 2008 [revised August 2012].

[44] Jørgensen $\mathrm{H}$ et al. Liquefaction of lignocellulose at high-solids concentrations. Biotechnol Bioeng 2007:96(5):862-70.

[45] Wood TM, Bhat MK. Methods for measuring cellulase activities. Methods Enzymol 1988;160:87-112.

[46] Bailey MJ, Tahtiharju J. Efficient cellulase production by Trichoderma reesei in continuous cultivation on lactose medium with a computer-controlled feeding strategy. Appl Microbiol Biotechnol 2003;62(2-3):156-62.

[47] Claeyssens M, Aerts G. Characterization of cellulolytic activities in commercial Trichoderma reesei preparations - an approach using small, Chromogenic Substrates. Bioresour Technol 1992;39(2):143-6. 